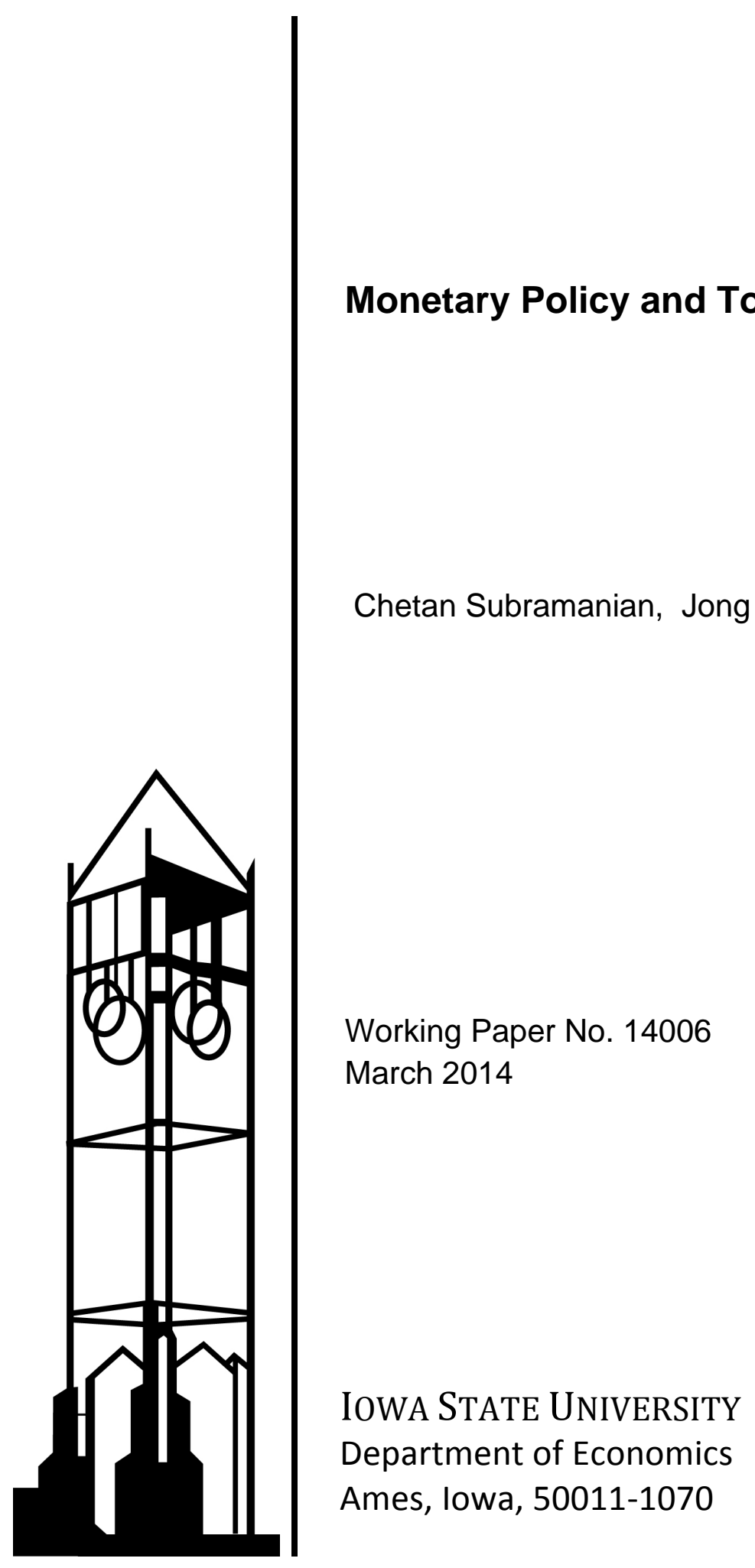

lowa State University does not discriminate on the basis of race, color, age, religion, national origin, sexual orientation, gender identity, genetic information, sex, marital status, disability, or status as a U.S. veteran. Inquiries can be directed to the Director of Equal Opportunity and Compliance, 3280 Beardshear Hall, (515) 294-7612. 


\title{
Monetary Policy and Tobin Taxes: A Welfare Analysis
}

\author{
Jong Kook Shin ${ }^{1} \quad$ Rajesh Singh ${ }^{2} \quad$ Chetan Subramanian $^{3}$
}

\begin{abstract}
This paper studies the choice of monetary policy regime in a small open economy under productivity shocks and noise traders in forex markets. We focus on two simple rules: fixed exchange rates and inflation targeting. We contrast the above two rules against optimal policy with commitment. In general, the presence of noise traders increases the desirability of a fixed exchange rate regime. We also evaluate the welfare impact of Tobin taxes on capital flows. These taxes help unambiguously in the absence of productivity shocks; their welfare impact under productivity shocks depends on the monetary regime in place and the trade elasticity between domestic and foreign goods.
\end{abstract}

KEywords: Noise traders; Fixed exchange rates; Tobin taxes; Optimal monetary policy. JEL Classification: E42, E52, F41

\section{Introduction}

There exists a large body of literature on market microstructure models that examine the role of noise traders in generating excess volatility in the foreign exchange (forex) market. This paper incorporates noise traders into a New Keynesian model of a small open economy with incomplete markets. We welfare-rank two simple rules, namely fixed exchange rate (PEG) and inflation targeting (IT), by identifying the rule that in terms of welfare is closest to the optimal monetary policy under commitment. In addition, we examine the welfare implications of imposing Tobin taxes on capital flows.

We show that the differences in welfare across these regimes can be mapped with the real exchange rate volatility that the regimes allow relative to what the optimal policy calls for. Optimal policy requires stabilizing real exchange rates in the presence of noise traders. As a result, a PEG outperforms an IT regime under productivity shocks and noise traders. Real exchange rates can also be stabilized by using Tobin taxes. However, these taxes improve welfare only under IT regime when domestic and foreign goods are substitutes in household consumption. When the two goods are compliments, Tobin taxes improve welfare under both regimes.

Our work is related to Jeanne and Rose (2002) who in a flexible price setup show that it is optimal to stabilize the exchange rate as floating exchange rates attract noise traders and increase overall volatility. Their paper thus rationalizes the benefit of having a credible fixed exchange rate regime. Shi and Xu (2009) build on Jeanne and Rose (2002) and show that Tobin taxes affect exchange rate volatility by affecting the relative population of noise traders in the forex market. However, these two papers have no output or inflation dynamics and rely on ad-hoc welfare metrics.

\footnotetext{
${ }^{1}$ Management School, 25 University Square, Queen's University Belfast, Belfast, BT7 1NN, Northern Ireland, UK; E-mail: j.shin@qub.ac.uk; Phone: +44-(0)28-9097-3297; Fax: +44-(0)28-9097-5156

${ }^{2}$ Department of Economics, Iowa State University, Ames IA 50011-1070; Email: rsingh@iastate.edu; Phone: (515)294-5213

${ }^{3}$ Corresponding author: Department of Economics and Social Sciences, IIM, Bangalore, Bannergatta Road, India 560076. E-mail: chetan.s@iimb.ernet.in, Phone: (91)-80-26993345.
} 
Our framework, on the other hand, generates endogenous dynamics including an expectational IS and Phillips curve. Optimal policy maximizes a quadratic approximation of the household's utility, a feature of recent papers on optimal monetary policy in small open economies (see, for example, Gali and Monacelli, 2005; De Paoli, 2009a and 2009b). This not only facilitates a simple insightful presentation of optimal policies, but also permits a straightforward comparison of simple ad-hoc rules. Our work is closely related with De Paoli (2009b) who shows that in a small open economy with incomplete markets a domestic IT regime outperforms a PEG when the elasticity of substitution between domestic and foreign goods is high, and vice versa when the elasticity is low. In contrast, we show that with noise in the forex market a PEG dominates an IT regime unambiguously.

The rest of the paper proceeds as follows. Section 2 develops the basic model with noise traders. Section 3 studies and welfare ranks the alternative monetary policy regimes. Section 4 provides a summary of the results and concludes.

\section{The Model}

\subsection{Households}

Our model is a small open economy (henceforth, Home) with incomplete markets that closely follows De Paoli (2009b). The world economy (henceforth, Foreign) is populated with a continuum of household of unit mass, where the fraction of the population in the segment $[0, n)$ belongs to Home and the remainder in the segment $[n, 1]$ belongs to Foreign. The utility function of a representative Home household is

$$
U_{t}=E_{t} \sum_{s=t}^{\infty} \beta^{s-t}\left[\frac{C_{t}^{1-\rho}}{1-\rho}-\frac{1}{n} \int_{0}^{n} \frac{\epsilon_{t}^{-\eta}\left(y_{t}^{j}\right)^{1+\eta}}{1+\eta} d j\right]
$$

where $C_{t}$ is individual consumption, $\rho$ is the coefficient of relative risk aversion, $\eta$ is the inverse of the elasticity of labor supply, and $\epsilon$ is a random productivity shock. The household produces a continuum of goods $[0, n]$ and $y^{j}$ denotes her output of good $j$. The consumption aggregate for a Home consumer is defined as:

$C=\left[\nu^{1 / \theta} C_{H}^{\frac{\theta-1}{\theta}}+(1-\nu)^{1 / \theta} C_{F}^{\frac{\theta-1}{\theta}}\right]^{\frac{\theta}{\theta-1}} ; C_{H}=\left[\frac{1}{n} \int_{0}^{n} c(z)^{\frac{\sigma-1}{\sigma}}\right]^{\frac{\sigma}{\sigma-1}} ; C_{F}=\left[\frac{1}{1-n} \int_{n}^{1} c(z)^{\frac{\sigma-1}{\sigma}}\right]^{\frac{\sigma}{\sigma-1}}$.

The parameter $\theta>0$ is the elasticity of substitution between consumption of Home- and Foreignproduced goods (henceforth, trade elasticity), $C_{H}$ and $C_{F}$, respectively; $\sigma$ is the elasticity of substitution within goods produced at Home as well as within goods imported from Foreign. The parameter determining Home consumer's preferences for Foreign goods, $1-v$, is a function of the relative size of Foreign, $1-n$, and of the degree of openness, $\lambda$. Specifically, $1-\nu=(1-n) \lambda$. This specification gives rise to home bias in consumption, as a result of which there are deviations from purchasing power parity. Foreign preferences are defined symmetrically with $\nu^{*}=n \lambda$; to differentiate from Home, its variables are denoted with an asterisk.

Let $P_{H}$ and $P_{F}$ denote the price indices for Home- and Foreign-produced consumption aggre- 
gates, respectively, and let $P$ denote the price index for Home's overall consumption aggregate. ${ }^{4}$ Then the real exchange rate can be expressed as $Q \equiv \frac{S P^{*}}{P}$, where $P^{*}$ is the Foreign counterpart of $P$, and $S$ is the nominal exchange rate in terms of Home currency per unit of Foreign currency. Finally, let $Y$ denote the Home output. Then, the demand side of the small open economy (as $n \rightarrow 0$ ) can be written in the log-linear form, with small case letters denoting log deviations from steady states of their corresponding upper case variables, $\mathrm{as}^{5}$

$$
y_{t}=(1-\lambda) c_{t}+\lambda c_{t}^{*}+\gamma q_{t}
$$

where $\gamma=\theta \lambda(2-\lambda) /(1-\lambda)$.

Prices are set following the standard Calvo formulation and the supply side of the economy can be represented in the log-linear form as

$$
\pi_{t}=k\left(\rho c_{t}+\eta y_{t}+\frac{\lambda}{1-\lambda} q_{t}-\eta \epsilon_{t}\right)+\beta E_{t} \pi_{t+1}
$$

where $\pi$ denotes the domestic (producer) price inflation; $k \equiv(1-\alpha \beta)(1-\alpha) / \alpha(1+\sigma \eta)$, where $\alpha$ is the fraction of firms that does not change prices.

\subsection{International bond market}

To introduce noise traders into the model, we first assume that Home households cannot directly participate in Foreign bond market but they can trade domestically in risk free bonds $(B)$ denominated in Home currency. The budget constraint of the Home household is given by

$$
P_{t} C_{t}+\frac{B_{t}}{1+i_{t}}=\Pi_{t}^{f}+B_{t-1}+\left(1-T_{t}\right) P_{H, t} Y_{t}+P_{H, t} T r_{t}
$$

where $i_{t}$ is the nominal interest rate, $T_{t}$ is the income tax, and $T r_{t}$ are lump-sum transfers from the government. While households trade in the Home-currency bond market, trade in Foreign-currency bonds is carried out by specialized forex dealers who trade in the interest of households by utilizing households' investments in the Home-currency bond market. Thus, $\Pi_{t}^{f}$ in $(5)$ above denotes net profit of forex traders that they fully rebate to the households.

Following Jeanne and Rose (2002), forex traders are modelled as overlapping generation of investors who live for two periods. In the first period they borrow funds from the households and purchase Foreign-currency bonds $B_{F}$. In the second period, they liquidate foreign bonds to repay loans from Home bond market, and transfer their profits net of taxes to households' accounts. To avoid non-stationarity in the model, following Schmidtt-Grohé and Uribe (2003), we assume that Foreign interest rate earned by forex traders is subject to an intermediation cost, $\psi$, decreasing (increasing) in traders' real foreign asset (debt) position, i.e., $\psi^{\prime}<0$. Specifically, gross Foreign interest rate earned by traders is $1+\widehat{i}_{t}^{*}=\left(1+i_{t}^{*}\right) \psi\left(\frac{B_{F, t} S_{t}}{P_{t}}\right)$, where $i_{t}^{*}$ is the nominal interest for

\footnotetext{
${ }^{4}$ Following $(2), \quad P=\left[\nu P_{H}^{1-\theta}+(1-\nu) P_{F}^{1-\theta}\right]^{1 /(1-\theta)} ; \quad P_{H}=\left[\frac{1}{n} \int_{0}^{n} p(z)^{1-\sigma} d z\right]^{1 /(1-\sigma)}$ and $P_{F}=$ $\left[\frac{1}{1-n} \int_{n}^{1} p(z)^{1-\sigma} d z\right]^{1 /(1-\sigma)}$, where $p(z)$ is the price of good $z$.

${ }^{5} \mathrm{~A}$ detailed version of our paper where all derivations have been provided is available at http://ssrn.com/abstract $=2241262$
} 
Foreign residents. ${ }^{6}$ Thus, a Home forex trader born in period $t-1$ borrows and invests $\frac{S_{t-1} B_{F, t-1}}{1+\widehat{i}_{t-1}^{*}}$ of Home currency to receive $B_{F, t-1}$ units of foreign currency in $t$. After repaying $\frac{S_{t-1} B_{F, t-1}}{1+\widehat{i}_{t-1}^{*}}\left(1+i_{t-1}\right)$ to its lenders, the trader's net Home-currency return per unit of Foreign bonds is:

$$
\varpi_{t}=S_{t}-S_{t-1} \frac{1+i_{t-1}}{1+\widehat{i}_{t-1}^{*}}
$$

To evaluate Tobin taxes as a policy instrument, we assume that a trader purchasing $B_{F, t}$ pays real foreign capital trading tax of $\Phi_{t}=\frac{\tau}{2}\left(\frac{S_{t} B_{F, t}}{P}\right)^{2}$ levied and collected by the government in units of Home goods. ${ }^{7}$ As a result, a trader $j$ born at $t$ maximizes the expected present value of profits:

$$
\max _{B_{F, t}} E_{t}^{j}\left[\beta\left(\frac{C_{t+1}}{C_{t}}\right)^{-\rho} \frac{P_{t}}{P_{t+1}}\left\{\varpi_{t+1} B_{F, t}^{j}-P_{H, t} \frac{\tau}{2}\left(\frac{S_{t} B_{F, t}^{j}}{P_{t}}\right)^{2}\right\}\right]
$$

where $E_{t}^{j}$ refers to the conditional expectation of trader $j$ at time $t .^{8}$ The trader's optimal choice of $B_{F, t}^{j}$ follows from

$$
E_{t}^{j}\left[\beta\left(\frac{C_{t+1}}{C_{t}}\right)^{-\rho} \frac{P_{t}}{P_{t+1}}\left\{\varpi_{t+1}-\tau \frac{S_{t}^{2} B_{F, t}^{j}}{P_{t}} \frac{P_{H, t}}{P_{t}}\right\}\right]=0,
$$

which shows that the traders' optimal investment depends upon their exchange rate expectations and, as one would expect, the demand for foreign bonds is decreasing in the Tobin tax. Following De Long et al. (1990), we assume that a fraction $G \in[0,1]$ of the forex dealers are noise traders. Their expectations about the future real exchange rate are noisy in the sense that they may deviate from the rational expectations by a noise shock. This leads to differences in the expectations between noise traders and informed traders resulting in irrational, non-fundamentals-driven trade. This non-fundamental trade is useful for discussing potential gains from financial transaction taxes: if noise trading introduces an excess volatility in the real economy, a transactions tax which may be expected to curb noise trading may thereby also reduce noise-trade-driven excess real volatility. Formally, the informed traders form the model-consistent rational forecast:

$$
E_{t}^{I}\left[q_{t+1}-q_{t}\right]=E_{t}\left[q_{t+1}-q_{t}\right],
$$

whereas the noise traders have

$$
E_{t}^{N}\left[q_{t+1}-q_{t}\right]=E_{t}\left[q_{t+1}-q_{t}\right]+v_{t},
$$

where $v_{t}$ is white noise with variance $\sigma_{v}^{2}$.

\footnotetext{
${ }^{6}$ As in De Paoli $(2009 \mathrm{~b})$, we assume that the spread $\widehat{i}_{t}^{*}-i_{t}^{*}$ is renumerated to the international intermediaries who rebate it equally among foreign housheolds.

${ }^{7}$ The assumption on $\Phi$ is standard in the literature and is made to prevent traders from receiving subsidies by taking a short position. We also assume that the Tobin tax is collected at the end of the period. This does not affect any of the qualitative implications.

${ }^{8}$ The trader $j$ 's ex-post profits that are transferred to the households are however given as

$$
\Pi_{j, t+1}^{f}=\varpi_{t+1} B_{F, t}^{j}-P_{H, t} \frac{\tau}{2}\left(\frac{S_{t} B_{F, t}^{j}}{P_{t}}\right)^{2}
$$

and $\Pi_{t+1}^{f}=\sum_{j} \Pi_{j, t+1}^{f}$.
} 


\subsection{Market Clearing}

Market clearing in the domestic bond market requires

$$
\frac{B_{t}}{1+i_{t}}=\frac{S_{t} B_{F, t}}{1+\widehat{i}_{t}^{*}}
$$

where the LHS is the amount of funds invested by households in Home bonds and the RHS is the Home-currency value of Foreign bonds purchased by forex traders. The government runs a balanced budget which implies

$$
P_{H, t}\left(T_{t} Y_{t}-T r_{t}\right)+P_{H, t-1} \Phi_{t-1}=0 .
$$

Combining (5), (10), and (11), we get the economy's current account which can be expressed in log-linear form as

$$
\beta b_{t}=b_{t-1}-\frac{\lambda}{1-\lambda} q_{t}+y_{t}-c_{t}
$$

Combining (7)-(9) we get

$$
i_{t}-i_{t}^{*}=E_{t} \Delta s_{t+1}+G v_{t}-(\tau+\delta) b_{t}
$$

where $G$ is the fraction of noise traders, $\delta$ denotes the elasticity of borrowing cost $\psi$ with respect to $\frac{B_{F, t} S_{t}}{P_{t}}$. Equation (13) is the uncovered interest parity condition between Home and Foreign economies. The noise term $v_{t}$ can alternatively be interpreted as shock to the risk premium purely due to forex market disturbances. ${ }^{9}$ In the last term, $-\delta b_{t}$ reflects that a higher bond holding reduces the interest premium $\hat{\imath}_{t}^{*}-i_{t}^{*}$ charged by foreign investors and by parity reduces the interest rate in the domestic bond market. A higher $\tau$, by reducing the demand for bonds, requires a lower $\hat{\imath}_{t}^{*}$ in equilibrium if $b_{t}$ is unchanged.

Equations (3), (4), (12), and (13) summarize the model's equilibrium conditions. An analogous set of expressions characterize the world economy. In what follows, we focus solely on shocks to Home economy and assume that the world economy is in steady state with $c_{t}^{*}=\pi_{t}^{*}=0$.

\section{Monetary Policy}

Having characterized the decentralized equilibrium, we are now set to evaluate and compare alternative monetary rules. Before studying the impact of noise trading on these rules under general preferences as specified in (1) and (2), we first nest our results with those highlighted by Gali and Monacelli (2005) and De Paoli (2009a, 2009b) for unit elasticity of intertemporal and intratemporal consumption substitution i.e., $\rho=\theta=1$. This particular case allows for a straightforward analytical exposition of optimal policies, as discussed below.

\subsection{Implementing efficient/flexible-price allocations under unit trade elasticity $(\theta=1)$}

Notice from (4) that with flexible prices, i.e., $\alpha=0$ and $k \rightarrow \infty$. The first term within brackets on the RHS of (4) represents the log deviation of real marginal cost (as a ratio of domestic prices)

\footnotetext{
${ }^{9}$ See, for example, Aldolfson (2008) and Dennis et. al. (2009).
} 
from its steady state value, i.e., the mark up. By keeping the real marginal cost fixed at its steady state mark up value implies $\pi_{t}=0$ for all $t$. Thus, complete price stability obtains flexible price allocations since firms have no desire to change prices. Under complete asset markets, Gali and Monacelli (2005) show that when intertemporal as well as intratemporal elasticities of consumption substitution equal unity, second order approximation of utility function is isomorphic to that in a closed economy: it is independent of terms of trade (and therefore the real exchange rates) and depends only upon domestic inflation and output gap. By stabilizing domestic inflation, output gap is also stabilized, and the first best is achieved. This is done by setting labor subsidies such that the effective steady state mark up equals $\frac{1}{1-\lambda}$ and then setting inflation to zero for all times. Essentially, this policy eliminates inefficiency due to monopolistic competition as well as due to price rigidities.

De Paoli (2009b) further shows that the above result is invariant to the structure of asset markets and continues to hold even under autarky when the trade elasticity $\theta=1 .{ }^{10}$ Since the welfare function in our model coincides with that obtained by De Paoli (2009b) when $\theta=1$, a policy of complete price stability continues to be efficient even when noise traders are present in forex markets.

\subsection{Optimal monetary policy when $\theta \neq 1$}

We now derive the policymaker's objective function as a second order approximation of the household's utility function and then study optimal monetary policy under commitment (with timeless perspective) when $\theta \neq 1$. This is the case studied by De Paoli (2009b) and our objective here is to show how the results change under noise trading in forex markets.

Following De Paoli (2009b), we derive the loss function of the central bank as a second order approximation of the utility function:

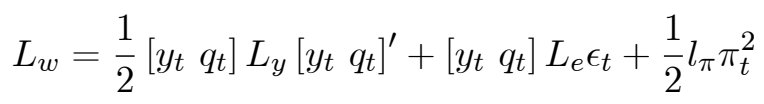

where $L_{y}=\left[l_{y y} l_{y q} ; l_{y q} l_{q q}\right], L_{e}=\left[l_{y \epsilon} ; l_{q \epsilon}\right]$. The coefficients $l_{\mathrm{s}}$ are functions of fundamental parameters of the economy. ${ }^{11}$ Essentially the loss function indicates that the central bank aims at balancing fluctuations in output, inflation, and real exchange movements. Intuitively, the presence of staggered prices and monopolistic competition implies there are gains in minimizing output and inflation fluctuations. In addition, in an open economy, there is an incentive to manage fluctuations in the real exchange rate to minimize the wedge between the marginal utility of consumption and the marginal utility of production.

As evident, with $\theta \neq 1$ a real exchange rate term appears in the welfare function. Then a policy of complete price stability is no longer optimal. ${ }^{12}$ The optimal policy now minimizes (14) subject to (3), (4), (12) and (13). As shown by De Paoli (2009b), in a special case where $\delta=\tau=0$, the

\footnotetext{
${ }^{10}$ That a perfect risk sharing occurs through terms of trade movements, even in the absence of asset trade, when home and foreign goods have a unit elasticity of substitution was first shown by Cole and Obstfeld (1991).

${ }^{11}$ See Appendix for details.

${ }^{12}$ With complete asset markets, De Paoli (2009a) shows that when $\theta>1$, the small open economy has an incentive to have its real exchange rate appreciated, which in equilibrium can be achieved by stabilizing real/nominal exchange rates. A real exchange rate appreciation shifts demand towards imports and thus causes less disutility from labor. Consumption does not suffer because of market completeness and welfare improves as a result. Conversely, a real depreciation works better when $\theta<1$.
} 
first order conditions for the problem can be summarized as ${ }^{13}$

$$
W_{q} E_{t} \Delta\left(q_{t+1}-q_{t+1}^{T}\right)+W_{y} E_{t} \Delta\left(y_{t+1}-y_{t+1}^{T}\right)+W_{\pi} E_{t} \pi_{t+1}=0
$$

where $X_{t+1}^{T}$ denotes a targeting value for variable $X$. According to the above rule, optimal policy responds to movements in output, inflation, and real exchange rate. Even though the weights $W$ of optimal policy are a function of the structural parameters of the model, one can show that the welfare is critically affected by the nature of the shock and the magnitude of the Tobin tax. It is worth noting that the efficient level of output in this case is given by $y_{t}^{T}=-\frac{\left(\gamma+\frac{1-\lambda}{\rho}\right)}{W_{y}} \epsilon_{t}$ and therefore a function only of productivity shocks, the target level of real exchange rate is zero (see appendix for details).

In the absence of noise traders, i.e., with $G=0$ in equation (13), De Paoli (2009b) has shown - in a complete reversal of the results obtained under complete asset markets in De Paoli (2009a) - that domestic inflation targeting dominates fixed exchange rates under productivity shocks for sufficiently high trade elasticities with $\theta>1 .^{14}$

\subsection{Monetary policy under noise trading in forex markets}

We now contrast an IT regime $\left(i_{t}=\chi \pi_{t}\right)$ and a PEG $\left(\Delta s_{t}=0\right)$ with the optimal policy characterized by (15). ${ }^{15}$ Below, we perform numerical simulations and compare equilibrium dynamics of inflation, output, consumption, and real exchange rates, in order to build intuition and quantify welfare losses under the two rules relative to the optimal policy under commitment with the timeless perspective (Woodford 1999). Following much of the literature (see, for example, Gali and Monacelli (2005), De Paoli (2009a, 2009b)) we compute the loss function under optimal policy as well as for the two rules IT and PEG by evaluating their unconditional expectations. ${ }^{16}$ We then evaluate the impact of Tobin taxes on welfare.

Our objective is to evaluate policies when the economy is subject to productivity shocks $\epsilon_{t}$ and there are noise traders in the forex market. To build intuition, however, we first evaluate welfare under alternative policies in the presence of noise traders but without productivity shocks, then under productivity shocks but no noise traders. Finally, we rank the two rules when both shocks occur simultaneously.

The exercises below are conducted with the baseline parameters shown in Table 1. To avoid clutter, we study impulse responses (with one shock at a time) for the case with $\theta>1$ by setting $\theta=1.5$. With both shocks in the model, we present the welfare and volatility results for $\theta=2$ as well as $\theta=0.5$.

\footnotetext{
${ }^{13}$ As has been extensively noted in the literature there are challenges to implementing this as a rule as there are issues of determinacy that crop up.

${ }^{14}$ Here, unlike under complete markets, an exchange rate stabilization by appreciating real exchange rate reduces demand for domestic goods and its negative income effect more than erodes the welfare gains from reduced disutility of labor.

${ }^{15}$ De Paoli (2009b) considers a strict inflation targeting rule wherein domestic inflation is always set to zero. However, as has been documented in the literature, there are challenges to implementing this policy as a simple rule and issues related with determinacy crop up. We therefore adopt the more practical flexible inflation targeting rule.

${ }^{16}$ Using unconditional expectation essentially eliminates the timeless perspective policy's dependence on the initial state. There is a debate in the literature on the choice of unconditional welfare measure vis-à-vis its conditional measure in this case. Dennis (2010) proposes an alternative measure of conditional loss and then shows that under this measure discretion outperforms timeless perspective policy. We compare optimal committment policy with the two rules IT and PEG (with committment), and the exercises we undertake are consistent with this objective. As we do not study discretionary policy, we feel that the issues raised by Dennis (2010) are not germane to our paper.
} 


\subsubsection{With noise traders, without productivity shocks}

Consider a temporary increase in risk premium shock, $v_{t}$. The efficient level of output without a productivity shock however remains unchanged. Therefore, the optimal policy calls for insulating the real side of the economy. Figure 1.A shows that the movement in inflation, output and real exchange rates are minimal under optimal policy. Intuitively, the depreciation of the real exchange rate due to a rise in $v_{t}$ increases aggregate demand. In order to stabilize demand, optimal policy raises interest rate to lower domestic consumption that implies higher savings and higher bond holdings. A rise in interest rate thus stabilizes output as well as inflation. In addition, a rise in interest rate by raising expected exchange rate appreciation partially offsets the real depreciation. It is easily checked that a rise in interest rate along with a real depreciation and increase in bond holdings is consistent with (13).

In contrast, real exchange depreciates substantially under the IT regime leading to a sharp increase in demand. The dynamics under the PEG are similar to those exhibited under optimal policy. The PEG, by stabilizing exchange rate allows the interest rate to absorb the rise in $v_{t}$. The consequent rise in interest rate stabilizes domestic demand and inflation. This can be seen in Table 2, which reports the standard deviations and the welfare loss, expressed as a percentage of steady state consumption, under the alternative monetary regimes. The lower inflation and output variability under the PEG brings it closer to the optimal policy and as a result it outperforms the IT regime.

Table 2 shows that welfare under all regimes improves with an increase in Tobin tax. Intuitively, an increase in Tobin tax reduces the demand for foreign bonds while a rise in $v_{t}$ increases the demand for foreign bonds. Ceteris paribus, raising Tobin taxes offsets rise in $v_{t}$ in the forex market. Required policy interest rate changes are muted as a result, in turn, without much affecting output and inflation.

\subsubsection{With productivity Shocks, without noise traders}

Now consider a temporary rise in productivity, $\epsilon$. Figure 1.B shows that under an optimal policy inflation stays flat while the output rises. Intuitively, a rise in productivity calls for an increase in output due to an increase in its efficient level. This is engineered by a decrease in policy interest rate that also lets real exchange rate depreciate. As a result, the demand for Home goods rises thus raising its output. Since output, domestic consumption, and real exchange rate comove with the productivity shock, the real marginal cost and inflation (see (4)) remain stabilized.

Since the optimal policy entails inflation stabilization, the dynamics exhibited by the IT regime closely mimic those under the optimal policy. The PEG on the other hand, by unduly stabilizing real exchange rate (Table 2), constrains interest rate and output movements. It leads to a substantial deflation and muted rise in domestic consumption and Home output. As a result, as in De Paoli (2009b), the IT regime welfare dominates a PEG (Table 2 ).

As evident from Table 2, a positive Tobin tax reduces welfare under all regimes. Intuitively, as savings (and bond holdings) comove with productivity shock (income effect) a positive Tobin tax stabilizes nominal (and therefore real) exchange rates excessively relative to what optimality commands. ${ }^{17}$

\footnotetext{
${ }^{17}$ As can be seen from (13), for a given intreest rate, a postive Tobin tax requires an appreciation (depreciation) under positive (negative) productivity shock if $b$ comoves with $\epsilon$.
} 


\subsubsection{With productivity shocks and noise trading in forex markets}

Consider now the following structure of shocks

$$
\begin{aligned}
\epsilon_{t} & =\rho_{\varepsilon} \epsilon_{t-1}+e_{\epsilon, t}, \\
v_{t} & =e_{v, t}
\end{aligned}
$$

where $e_{\epsilon, t}$ and $e_{v, t}$ are uncorrelated i.i.d. white noise shocks.

Table 3 clearly indicates that under this scenario the PEG dominates the IT regime for $\theta=2$ as well as $\theta=0.5$. For $\theta>1$, productivity shocks call for real exchange rate flexibility with inflation stability, whereas the risk premium shocks require the opposite. For the shock variances exhibited in Table 1, it turns out that risk premium shock takes precedence over productivity shock in the determination of optimal policy response. As a result, the PEG dominates the IT regime for $\theta=2$.

Table 3 shows that when $\theta=2$, a positive Tobin tax lowers welfare under the PEG while the reverse is the case under the IT regime. Recall from our preceding discussion that with only productivity shocks (but no noise traders) the IT regime outperforms the PEG; now it is the presence of noise traders in addition that makes the PEG superior. Imposing Tobin taxes in addition stabilize real exchange rate excessively and thus reduce welfare under the PEG. In contrast, since the IT regime performs poorly precisely because of real exchange rate instability, Tobin taxes improve the regime's performance.

That the PEG dominates the IT regime for $\theta=0.5$ comes as no surprise since De Paoli (2009b) has shown this to hold for a sufficiently low $\theta$ even without noise traders. The logic offered is that (i) stabilizing real exchange rate causes its appreciation and (ii) with incomplete markets and with Home and Foreign goods being complements, a real exchange rate appreciation improves welfare through a positive income effect. As a result, the relative desirability of PEG vis-à-vis IT increases further when $\theta=0.5$ relative to $\theta=2$. As evident in Table 3 , imposing Tobin taxes further improve welfare by stabilizes real exchange rates, irrespective of the regime in place. ${ }^{18}$

\section{Conclusions}

The objective of this paper is twofold. First, we rank two classic rules, fixed exchange rates and inflation targeting, in a small open economy with incomplete markets and noise traders in the forex market. Second, we evaluate the impact of Tobin taxes under each of these two rules.

The key message of the paper is that the presence of noise traders in the forex market increases the desirability of fixed exchange rates vis-à-vis inflation targeting, irrespective of the trade elasticity between domestic and foreign goods. More specifically, with noise traders in the forex market and with shocks to productivity, a fixed exchange rate regime dominates inflation targeting even when the two goods are substitutes, reversing the result highlighted by De Paoli (2009b). The simple intuition is that the presence of noise traders generate excess volatility of real exchange rates, which is neutralized by fixing exchange rates.

Tobin tax acts as an additional instrument to stabilize real exchange rates further. When domestic and foreign goods are substitutes, these taxes overstablize the real exchange rate under

\footnotetext{
${ }^{18}$ Our results are robust to changes in the variance and persistence of risk premium shocks as well as trade openness and activeness of IT policy. The results are not reported here due to space limitations. They can be obtained from the authors on request.
} 
a fixed exchange rate regime and perform poorly, whereas under inflation targeting they improve welfare by providing some stability to the real exchange rate. On the other hand, when the domestic and foreign goods are complements, Tobin taxes improve performance irrespective of the regime in place - a result which is in line with the findings in De Paoli (2009b).

A shortcoming of this paper is that the number of noise traders is assumed to be exogenous. One potential direction for future research would be to endogenize the entry of noise traders and reevaluate the performance of the two classic rules and Tobin taxes within this paper's setup.

\section{References}

[1] Adolfson, Malin, (2007) "Incomplete exchange rate pass-through and simple monetary policy rules," Journal of International Money and Finance, Vol. 26, 468-94

[2] Cole, L. Harold and Maurice Obstfeld, (1991) "Commodity trade and international risk sharing: how much do financial markets matter?" Journal of Monetary Economics, Vol. 28(1), $3-24$

[3] De Long, J. Bradford, Andrei Shleifer, Lawrence H. Summers and Robert J. Waldmann, (1990) "Noise Trader Risk in Financial Markets," The Journal of Political Economy, Vol. 98(4), 703738 .

[4] De Paoli, Bianca, (2009a) "Monetary Policy and Welfare in a Small Open Economy," Journal of International Economics, Vol. 77(1)

[5] De Paoli, Bianca, (2009b) "Monetary Policy in a Small Open Economy: the Role of the Asset Market Structure," Journal of Money, Credit and Banking, Vol. 41(7)

[6] Dennis, Richard, (2010) "When is discretion superior to timeless perspective policymaking?," Journal of Monetary Economics, Vol. 57, 266-77

[7] Dennis, Richard, Leitemo, Kai, and Ulf Sodestorm, (2009) "Monetary Policy in a Small Open Economy with a Preference for Robustness," Working paper 2007-04, Federal Reserve Bank of San Francisco Working Paper Series

[8] Gali, Jordi and Tommaso Monacelli (2005) "Monetary Policy and Exchange Rate Volatility in a Small Open Economy," Review of Economic Studies, Vol. 72(3), 707-734

[9] Jeanne, Olivier, and Andrew K. Rose (2002) "Noise trading and exchange rate regimes," Quarterly Journal of Economics, Vol. 117, 537-69

[10] Schmitt-Grohé, Stephanie and Martín Uribe, (2003) "Closing small open economy models," Journal of International Economics, Vol. 61(1), 163-185

[11] Shi, Kang, and Jenny Xu (2009) " Entry Cost, Tobin Tax, and Noise Trading in the Foreign Exchange Market," Canadian Journal of Economics, Vol. 42(4) , 1501-1526

[12] Woodford, Michael, (1999) "How should monetary policy be conducted in an Era of price stability?" Federal Reserve Bank of Kansas City, New Challenges for Monetary Policy, Kansas City 


\section{Appendix}

\section{Loss Function}

The coefficients of the loss function are ${ }^{19}$

$$
\begin{gathered}
l_{y y}=\frac{(-1+\mu+\eta \mu+\rho)\left(\eta(1+\theta(-2+\lambda))(-1+\lambda)^{2}-\left(-1+\lambda+\theta\left(2-5 \lambda+2 \lambda^{2}\right)\right) \rho\right)}{(-1+\lambda)^{2} \mu(\eta(1+\theta(-2+\lambda)-\lambda)+\rho-2 \theta \rho+\lambda(-1+\theta \rho))} \\
l_{y q}=\frac{\theta \lambda(-1+\mu+\eta \mu+\rho)\left(1+\lambda^{2}(3-4 \theta \rho)+\lambda^{3}(-1+\theta \rho)+\lambda(-3+4 \theta \rho)\right)}{(-1+\lambda)^{3} \mu(\eta(1+\theta(-2+\lambda)-\lambda)+\rho-2 \theta \rho+\lambda(-1+\theta \rho))} \\
l_{q q}=-\frac{\theta \lambda(-1+\mu+\eta \mu+\rho)\left(\begin{array}{c}
(-1+\lambda)^{2}\left(1-3 \lambda+\lambda^{2}\right)+\theta^{2}(-2+\lambda)^{3} \lambda \rho \\
-\theta(-1+\lambda)\left(-2+\lambda^{3}(1+\rho)-\lambda^{2}(5+4 \rho)+\lambda(6+4 \rho)\right)
\end{array}\right)}{(-1+\lambda)^{4} \mu(\eta(1+\theta(-2+\lambda)-\lambda)+\rho-2 \theta \rho+\lambda(-1+\theta \rho))} \\
l_{y \epsilon}=-\frac{\eta(1+\theta(-2+\lambda))(-1+\mu+\eta \mu+\rho)}{\mu(\eta(1+\theta(-2+\lambda)-\lambda)+\rho-2 \theta \rho+\lambda(-1+\theta \rho))} \\
l_{q \epsilon}=0
\end{gathered}
$$

See online Appendix for derivation.

\section{Optimal Policy}

For a special case where $\delta=\tau=0$, the optimal policy can be reduced to

$$
0=W_{q} E_{t} \Delta\left(q_{t+1}-q_{t+1}^{T}\right)+W_{y} E_{t} \Delta\left(y_{t+1}-y_{t+1}^{T}\right)+W_{\pi} E_{t} \pi_{t+1}
$$

where

$$
\begin{aligned}
& W_{y}=l_{y q}+\left(\gamma+\frac{1-\lambda}{\rho}\right) l_{y y}, \quad W_{q}=l_{q q}+\left(\gamma+\frac{1-\lambda}{\rho}\right) l_{y q} \\
& W_{\pi}=\left(\frac{1}{1-\lambda}\right)+\left(\gamma+\frac{1-\lambda}{\rho}\right) \eta \\
& y_{t}^{T}=-\frac{\left(\gamma+\frac{1-\lambda}{\rho}\right)}{W_{y}} \epsilon_{t}, \quad q_{t}^{T}=-\frac{l_{q \epsilon}}{W_{q}} \epsilon_{t}=0
\end{aligned}
$$

\footnotetext{
${ }^{19}$ The derivations have been provided in the detailed version of the paper.
} 
Table 1: Baseline Parameters

\begin{tabular}{lll}
\hline Parameter & Value & Remarks \\
\hline$\lambda$ & 0.4 & Trade openness \\
$\beta$ & 0.99 & Discount factor (annual real interest rate of 4\%) \\
$\eta$ & 1.6 & Inverse Frisch elasticity of labor supply \\
$\alpha$ & 0.75 & Calvo sticky price parameter: average of 4 quarters of price rigidity \\
$\theta$ & 1.5 & Elasticity of substitution between domestic and foreign goods \\
$\delta$ & 0.01 & Elasticity of risk premium with respect to foreign debt size \\
$\sigma$ & 6 & Elasticity of substitution among differentiated intermediate goods \\
$\rho$ & 2 & Coefficient of relative risk aversion \\
$\gamma$ & $\theta \lambda(2-\lambda) /(1-\lambda)$ & \\
$k$ & $(1-\alpha \beta)(1-\alpha) / \alpha(1+\sigma \eta)$ & \\
$\rho_{\epsilon}$ & 0.95 & Persistence of productivity shock \\
$\sigma_{\epsilon}, \sigma_{v}$ & 0.07 & Standard deviation of productivity and risk premium shocks \\
$\chi$ & 2.5 & Activeness of interest rate targeting \\
\hline
\end{tabular}

Table 2: Welfare Loss and Variance of Key Variables

\begin{tabular}{cccccc}
\hline $\begin{array}{c}\text { Policy } \\
\text { Risk premium Shock }\end{array}$ & Parameter & Welfare loss & $\operatorname{var}(\boldsymbol{q})$ & $\operatorname{var}(\boldsymbol{y})$ & $\operatorname{var}(\boldsymbol{\pi})$ \\
\hline IT & $\tau=0$ & 0.0018 & $9.95 \mathrm{E}-04$ & $2.54 \mathrm{E}-03$ & $6.17 \mathrm{E}-07$ \\
PEG & & $-4.45 \mathrm{E}-07$ & $9.26 \mathrm{E}-07$ & $8.78 \mathrm{E}-05$ & $1.05 \mathrm{E}-07$ \\
OP & & -0.00022 & $8.34 \mathrm{E}-05$ & $5.41 \mathrm{E}-05$ & $2.00 \mathrm{E}-09$ \\
\hline IT & $\tau=0.01$ & 0.0017 & $9.54 \mathrm{E}-04$ & $2.45 \mathrm{E}-03$ & $6.04 \mathrm{E}-07$ \\
PEG & & $-1.00 \mathrm{E}-06$ & $8.83 \mathrm{E}-07$ & $8.56 \mathrm{E}-05$ & $1.00 \mathrm{E}-07$ \\
OP & & -0.00021 & $7.95 \mathrm{E}-05$ & $5.11 \mathrm{E}-05$ & $2.07 \mathrm{E}-09$ \\
\hline Productivity Shock & & & & & \\
\hline IT & $\tau=0$ & -0.0155 & 0.0017 & 0.0117 & $1.23 \mathrm{E}-05$ \\
PEG & & -0.0130 & 0.0011 & 0.0083 & $8.97 \mathrm{E}-06$ \\
OP & & -0.0189 & 0.0018 & 0.0124 & $1.16 \mathrm{E}-08$ \\
\hline IT & \multirow{2}{*}{0.01} & -0.0131 & 0.0015 & 0.0112 & $1.50 \mathrm{E}-05$ \\
PEG & & -0.0121 & 0.0010 & 0.0081 & $8.18 \mathrm{E}-06$ \\
OP & & -0.0171 & 0.0016 & 0.0120 & $7.62 \mathrm{E}-09$ \\
\hline
\end{tabular}


Table 3: Welfare Loss and Variance When Both Shocks Are Turned On

\begin{tabular}{|c|c|c|c|c|c|c|}
\hline Policy & $\boldsymbol{\tau}=\mathbf{0}$ & Parameter & Welfare loss & $\operatorname{var}(q)$ & $\operatorname{var}(y)$ & $\operatorname{var}(\pi)$ \\
\hline IT & & $\theta=2$ & 0.1025 & 0.0464 & 0.1687 & $2.27 \mathrm{E}-04$ \\
\hline PEG & & & 0.0334 & 0.0017 & 0.0368 & 5.03E-05 \\
\hline IT & & $\theta=0.5$ & -0.2076 & 0.0078 & 0.0006 & $1.05 \mathrm{E}-05$ \\
\hline PEG & & & -0.4845 & 0.0016 & 0.0006 & $3.04 \mathrm{E}-06$ \\
\hline Policy & $\tau=0.01$ & Parameter & Welfare loss & $\operatorname{var}(q)$ & $\operatorname{var}(y)$ & $\operatorname{var}(\pi)$ \\
\hline IT & & $\theta=2$ & 0.0930 & 0.0407 & 0.1522 & $1.80 \mathrm{E}-04$ \\
\hline PEG & & & 0.0349 & 0.0015 & 0.0364 & 4.68E-05 \\
\hline IT & & $\theta=0.5$ & -0.3157 & 0.0089 & 0.0007 & $1.52 \mathrm{E}-06$ \\
\hline PEG & & & -0.5249 & 0.0016 & 0.0006 & $3.28 \mathrm{E}-06$ \\
\hline
\end{tabular}


Figure 1: Impulse Response of Key Variables

A. Risk Premium Shock
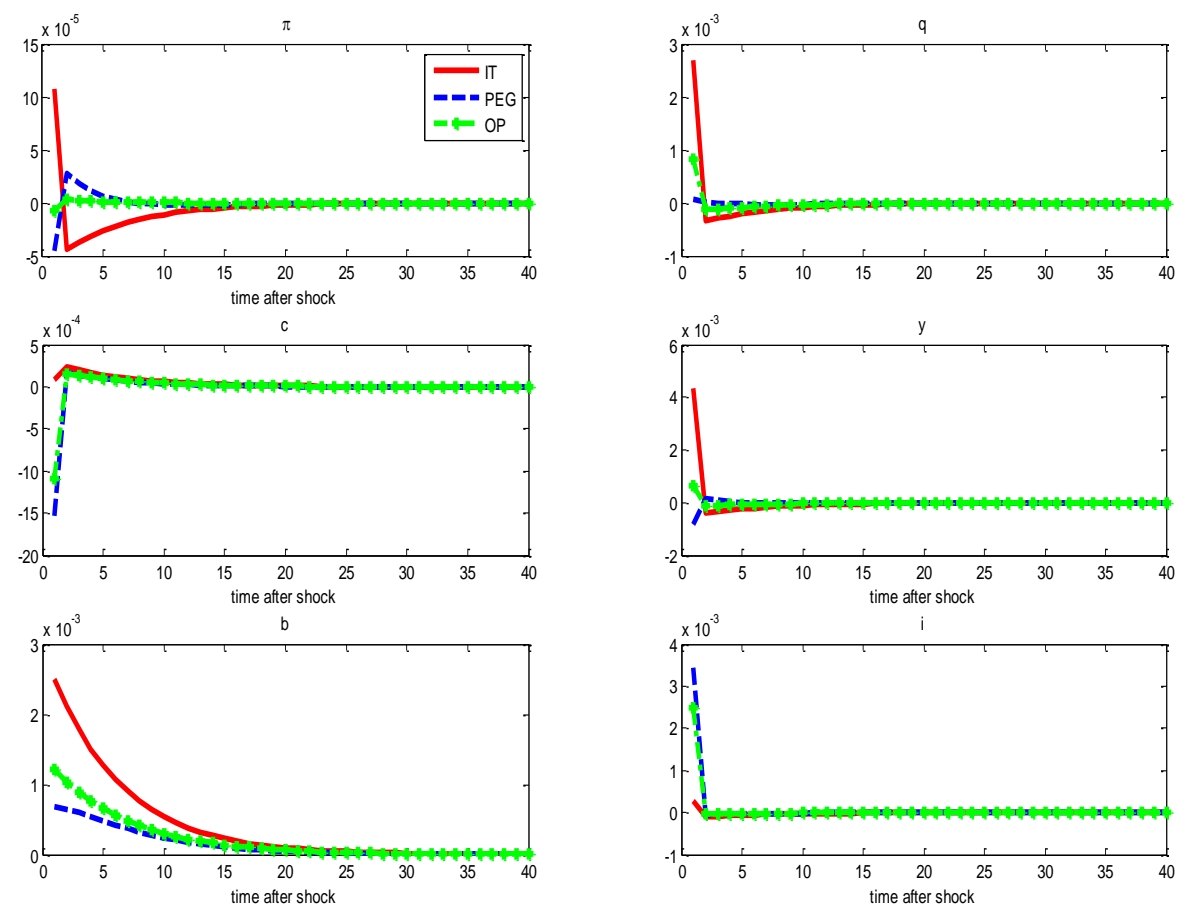

B. Productivity Shock
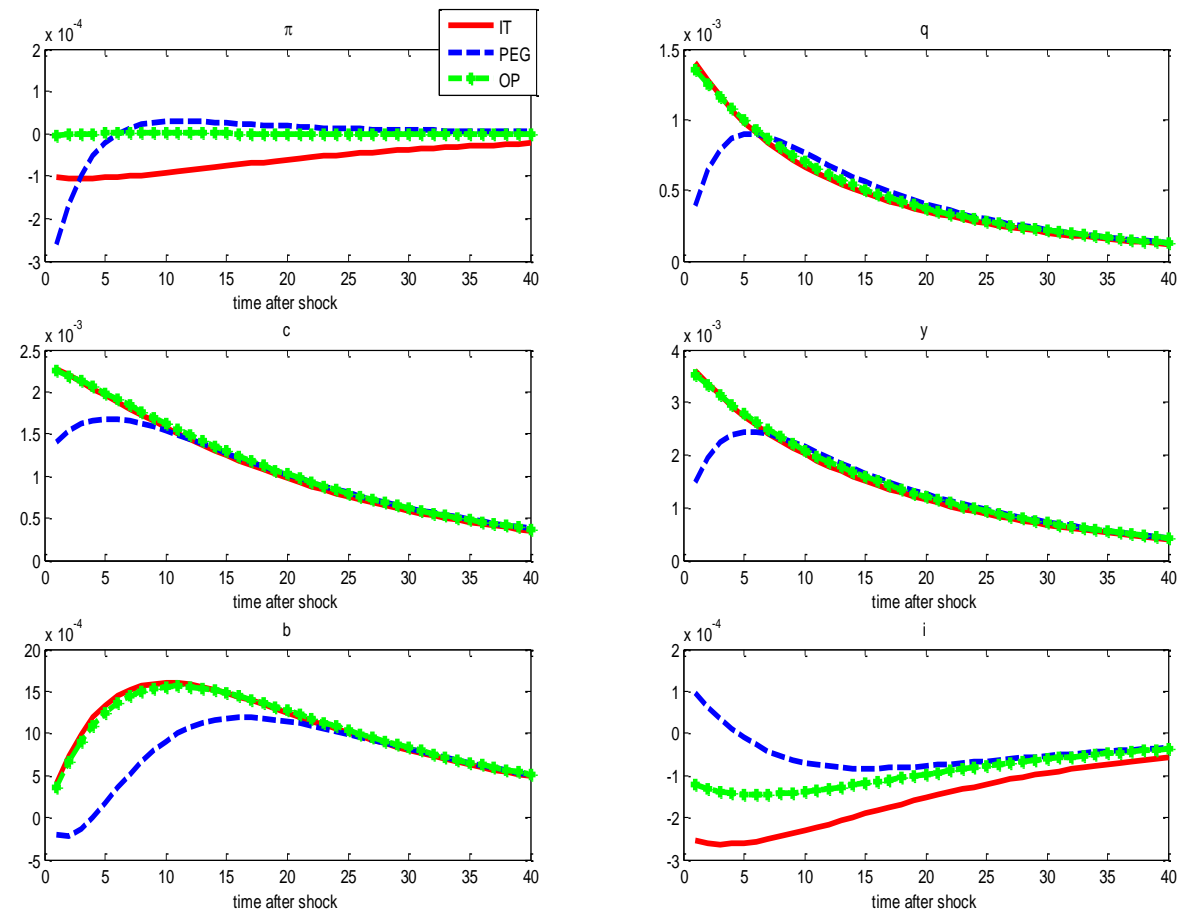